\title{
Pore Size Control of a Molecular Sieve Silica Membrane Prepared by a Counter Diffusion CVD Method
}

\author{
Mikihiro Nomura, Toshihiro NAgayo \\ and Keita MONMA \\ Department of Applied Chemistry, Shibaura Institute of Technology, \\ 3-7-5, Toyosu, Koto-ku, Tokyo 135-8548, Japan
}

Keywords: Silica Membrane, Counter Diffusion CVD, Pore Size Control, Silica Precursors

\begin{abstract}
A molecular sieve silica membrane was successfully prepared by using a counter diffusion chemical vapor deposition method. Effects of silica precursors on permeation properties through the silica membranes were investigated. Five types of silica alkoxides (tetramethyorthosilicate (TMOS), methyltrimethoxysilane (MTMOS), trimethylmethoxysilane (TMMOS), propyltrimethoxysilane (PrTMOS) and phenyltrimethoxysilane (PhTMOS)) were employed for the silica precursors. $\mathrm{H}_{2}, \mathrm{~N}_{2}$ and $\mathrm{SF}_{6}$ permeances were measured through the silica membranes at $300^{\circ} \mathrm{C} . \mathrm{H}_{2}$ permselective silica membranes were obtained from the smaller silica precursors such as TMOS, MTMOS or TMMOS. $\mathrm{H}_{2} / \mathrm{N}_{2}$ permecnces ratios were over 200 , while $\mathrm{N}_{2} / \mathrm{SF}_{6}$ permeances ratios were around 1 . According to the kinetic diameters of $\mathrm{H}_{2}(0.26 \mathrm{~nm}), \mathrm{N}_{2}(0.36 \mathrm{~nm})$ and $\mathrm{SF}_{6}(0.55 \mathrm{~nm})$, pore sizes of the membranes were about $0.3 \mathrm{~nm}$. $\mathrm{N}_{2}$ permselective silica membrane was obtained from the larger silica precursors such as PrTMOS or PhTMOS. $\mathrm{N}_{2} / \mathrm{SF}_{6}$ permeances ratios through the membranes prepared by PrTMOS or PhTMOS were 30 and 32, respectively. Those values are much larger than that of Knudsen diffusion $(2.3) \cdot \mathbf{H}_{2} / \mathbf{N}_{2}$ permeances ratios through the membranes were about 40 showing that the maximum pore sizes are around $0.5 \mathrm{~nm}$. These results show that the pore size of silica membranes can be controlled by changing the silica precursors. The PhTMOS membrane was confirmed as a silica membrane without carbon remaining by the cross-sectional XPS measurements.
\end{abstract}

\section{Introduction}

Recently, much attention has been paid to inorganic membranes for high temperature gas separations by ceramic membranes and metal membranes (i.e., Uemiya, 1999). Silica membranes are one of the popular ceramic membranes especially for hydrogen permselective membranes. These silica membranes have been prerpared by using a sol-gel method (Nair et al., 2000; Yoshino et al., 2005; Kanezashi and Asaeda, 2006) or a chemical vapor depsotion (CVD) method (Gavalas et al., 1989; Morooka et al., 1995; Prabhu and Oyama, 2000; Nomura et al., 2001). Hydrogen permselective inorganic membranes can be applied to membrane reactors such as steam reforming of methane (i.e., Kurungot et al., 2003; Tsuru et al., 2004; Nomura et al., 2006b). Developments of silica membrane modules are also reported both by a sol-gel method (Yoshino et al., 2005) and by a CVD method (Gopalakrishnan et al., 2006). Silica membranes for high temperature gas separations have been

Received on March 23, 2007; accepted on August 9, 2007. Correspondence concerning this article should be addressed to M. Nomura (E-mail address: Lscathy@shibaura-it.ac.jp).

Presented at International Symposium on Innovative Materials for Processes in Energy Systems, IMPRES, Kyoto, October, 2007. investigated by many research groups. However, most silica membranes reported are for hydrogen separation.

Pore size control of a molecular sieve membrane is one of the essential techniques for a membrane development. Developments of a molecular sieve membrane are one of the solutions for energy efficient processes. Several reports have been reported for molecular sieve silica membrane prepared by a sol-gel method. Raman and Brinker (1995) reported a novel template method to obtain molecular sieve silica membrane by using a copolymerization of tetraethoxysilnae (TEOS) and methyltriethoxysilane. Silica co-polymer was calcined at $550^{\circ} \mathrm{C}$, and methyl group in the copolymer was fired to obtain micropores. Kusakabe et al. (1999) used alkyltriethoxysilanes to control the pore size of silica membrane by changing the numbers of alkyl chains of the silica precursors. The mixtures of TEOS and dodecyltriethoxysilane (DTEOS) were employed for the silica source. Pore size of the silica membrane prepared only from TEOS was about $0.3 \mathrm{~nm}$ based on the single gas permeation tests, while pore size increased to $0.3-0.4 \mathrm{~nm}$ through the membrane prepared from the mixtures of TEOS and DTEOS. This is explained by the calcinations of the alkyl groups of DTEOS. Former reports for pore size control of silica membrane have been prepared by a sol-gel method. In this study, pore size control of the silica membrane by 


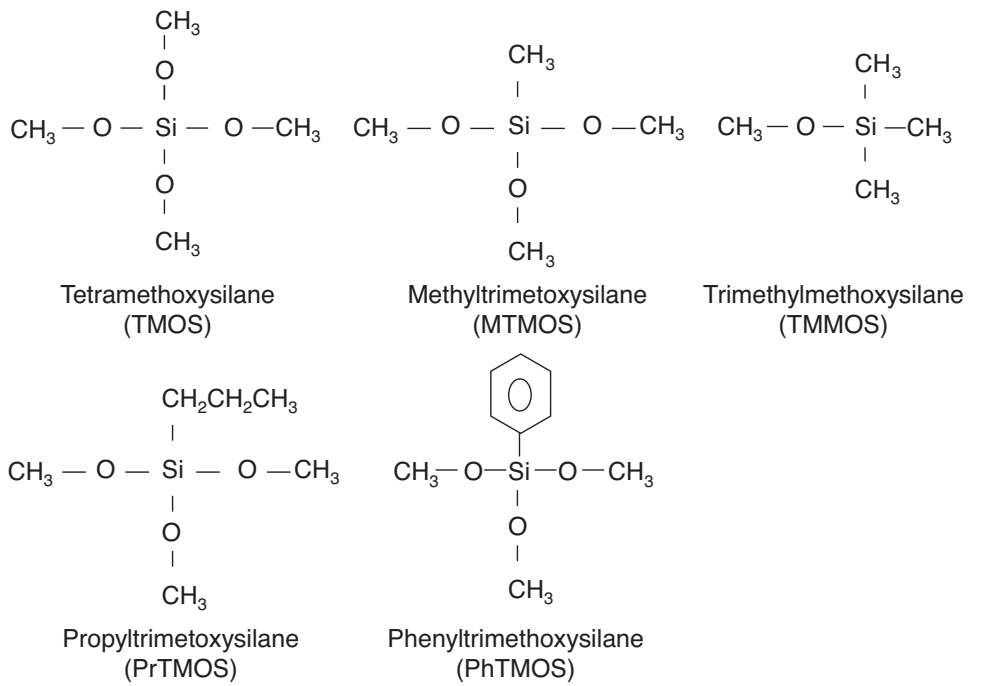

Fig. 1 Structural formulas of silica precursors

using a CVD method is investigated. There are two types of CVD methods by the difference of providing directions of porous substrate for silica precursor(s). One is a one side geometry method that a silica source vapor is provided from only one side of the porous substrate (Ha et al., 1993; Morooka et al., 1995; Lee et al., 2004; Oyama et al., 2004). The other is a counter diffusion CVD method that two precursors are provided from another side of the porous substrate (Gavalas et al., 1989; Nakao et al., 2000; Yamaguchi et al., 2000). Each precursor diffuses into the pore of the substrate and meets in the pores of the substrate. Deposition reaction occurs in the pore of the substrate, and the reaction stops due to the diffusion limitation by the deposited silica. Uniform membranes can be obtained by the counter diffusion method by this deposition mechanism. The group of the Tokyo University reported that hydrothermally stable silica membrane was prepared by the counter diffusion CVD method at $600^{\circ} \mathrm{C}$ using tetramethoxysilane (TMOS) and oxygen as precursors (Nomura et al., 2005a, 2005b, 2006a, 2006b). However, the effects of silica precursors on the membrane properties are not clear. In this report, alkylmethoxysilanes or phenyltrimethoxysilane were employed for silica precursors to obtain molecular sieve silica membranes that have larger pore size compared with the hydrogen permselective silica membrane. In order to obtain such a membrane, effects of numbers of alkyl groups or numbers of alkyl chain were discussed.

\section{Experimental}

Tetramethoxysilane (TMOS), methyltrimethoxysilane (MTMOS), trimethylmethoxysilane (TMMOS), propyltrimethoxysilane (PrTMOS) and phenyltrimethoxysilane (PhTMOS) were used as a silica pre-

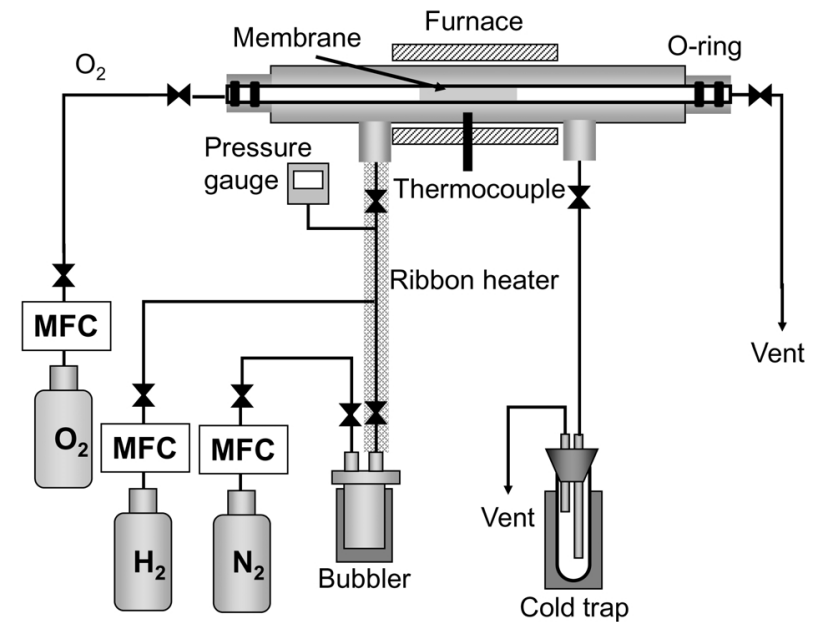

MFC: mass flow controller

Fig. 2 Schematic diagram of a counter diffusion CVD method

cursor (Shin-Etsu Chem. Co.). Figure 1 shows the chemical formulas of the silica precursors.

The difference of the precursors was an alkyl or a phenyl group in the chemical structures. Figure 2 shows the schematic diagram for the counter diffusion CVD method. A membrane module was placed in the center of the figure. Porous $\alpha$-alumina substrates (effective membrane area, $\phi=2.7 \mathrm{~mm}, L=50 \mathrm{~mm}$, pore size $0.1 \mu \mathrm{m}$ ) were provided by NOK Co. A $\gamma$-alumina layer having $4 \mathrm{~nm}$ pores was dipped on the $\alpha$-alumina substrates by a sol-gel method. A $\gamma$-alumina substrate was placed in the membrane module in the furnace. Both side of the substrate was sealed by viton o-rings. The deposition temperature was kept between 400 and $650^{\circ} \mathrm{C}$ that was controlled by the thermocouple placed in the center of the substrate. The temperature of the 
precursor bottle was controlled between 0 and $55^{\circ} \mathrm{C}$, and nitrogen was bubbled at the rate of $200 \mathrm{~mL} \mathrm{~min}^{-1}$ for the outside of the substrate. The lines between the bubbler and the membrane module were heated by ribbon heaters to prevent condensation of the silica precursors. One of the silica precursors was poured into the bubbler. The oxygen flow rate was kept at $200 \mathrm{~mL}$ $\mathrm{min}^{-1}$ for the inside of the substrate. CVD was carried out for 60 min except the PhTMOS deposition. PhTMOS was deposited for $100 \mathrm{~min}$. The single gas permeances of $\mathrm{H}_{2}, \mathrm{~N}_{2}$ or $\mathrm{SF}_{6}$ were measured at $300^{\circ} \mathrm{C}$ by a pressure change method. Kinetic diameters of $\mathrm{H}_{2}$, $\mathrm{N}_{2}$ and $\mathrm{SF}_{6}$ are $0.26 \mathrm{~nm}, 0.36 \mathrm{~nm}$ and $0.55 \mathrm{~nm}$, respectively. High $\mathrm{H}_{2} / \mathrm{N}_{2}$ permeances ratio through a membrane indicates that the pore size was controlled between 0.26 and $0.36 \mathrm{~nm}$, while high $\mathrm{N}_{2} / \mathrm{SF}_{6}$ permeances ratio show that the pore size was between 0.36 and $0.55 \mathrm{~nm}$.

Hydrothermal stability was also tested using the same apparatus shown in Figure 2. Pure water was poured into the bubbler and the bubbler temperature was kept at $92^{\circ} \mathrm{C}$. Nitrogen was introduced into the bubbler at the rate of $20 \mathrm{~mL} \mathrm{~min}^{-1}$ to keep the outside of the membrane to keep $75 \%$ of steam of an ambient pressure. The reactor temperature was kept at $500^{\circ} \mathrm{C}$. Stability was tested by $\mathrm{H}_{2}$ and $\mathrm{N}_{2}$ permeances measured after the steam treatment. This procedure was repeated till $60 \mathrm{~h}$ of the steam treatment.

\section{Results and Discussion}

\subsection{TMMOS deposition}

Deposition temperatures are very important parameters to obtain hydrogen permselective membrane. Activation energies $\left(E_{\text {act }}\right)$ of $\mathrm{H}_{2}$ permeation through the silica membrane prepared by TMOS increased with increasing deposition temperatures between 500 and $600^{\circ} \mathrm{C}$ (Nomura et al., 2006a). On the other hand, hydrogen permeances decreased with increasing deposition temperatures. This is explained that the density of the deposited silica increased with increasing deposition temperatures. Thus, higher $E_{\text {act }}$ shows the higher density of the deposited silica. TMMOS was employed for the silica source keeping the bubbler temperature at $0^{\circ} \mathrm{C}$. The density of deposited silica must be low due to 3 methyl groups of the TMMOS. Because, the reaction to obtain silica from the silica precursors should be dehydrated condensation of the methoxy groups. TMMOS has 3 methyl groups and only one methoxy group. The TMMOS deposition must be silica by oxidation of the methyl groups of the silica precursor. However, the silica structure must not be dense by the oxidation reaction. Figure 3 shows the permeation properties through the membrane prepared by keeping the TMMOS bubbler at $0^{\circ} \mathrm{C} . \mathrm{H}_{2}$ permeances decreased with increasing the deposition temperatures from 500 to $650^{\circ} \mathrm{C}$. This is the similar trend to the TMOS depo-
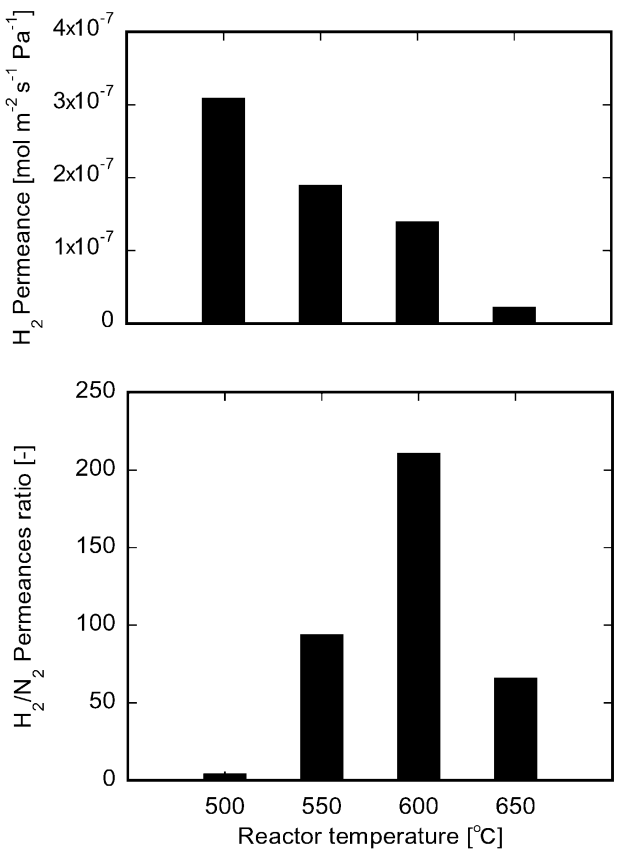

Fig. 3 Permeation properties through the silica membrane prepared from $0^{\circ} \mathrm{C}$ of TMMOS

sition in the former report (Nomura et al., 2006a), while $\mathrm{H}_{2} / \mathrm{N}_{2}$ peremances ratio shows the maximum value (211) at $600^{\circ} \mathrm{C}$ of deposition. $\mathrm{H}_{2} / \mathrm{N}_{2}$ permeances ratio was 4.5 at $500^{\circ} \mathrm{C}$ of the deposition that the value is almost same as the Knudsen diffusion value (3.7). The deposition temperature of $500^{\circ} \mathrm{C}$ was not enough for the TMMOS decomposition reaction. $\mathrm{H}_{2} / \mathrm{N}_{2}$ permeances ratio through the membrane deposited at $650^{\circ} \mathrm{C}$ was 66 that is about one third of the membrane deposited at $600^{\circ} \mathrm{C}$. The permeances ratio of $\mathrm{H}_{2} / \mathrm{N}_{2}$ was usually decided by the $\mathrm{H}_{2}$ permeances through the membrane, because $\mathrm{N}_{2}$ permeances through the deposited membranes were almost the same at around the lower detection limit of the apparatus. $\mathrm{H}_{2}$ permeance through the TMMOS membrane deceased from $1.4 \times$ $10^{-7} \mathrm{~mol} \mathrm{~m}^{-2} \mathrm{~s}^{-1} \mathrm{~Pa}^{-1}\left(600^{\circ} \mathrm{C}\right)$ to $2.3 \times 10^{-8} \mathrm{~mol} \mathrm{~m}^{-2} \mathrm{~s}^{-1}$ $\mathrm{Pa}^{-1}\left(650^{\circ} \mathrm{C}\right)$. In order to obtain larger pores, both $\mathrm{H}_{2}$ and $\mathrm{N}_{2}$ permeances should increase. It is difficult to obtain larger pore size membrane by using TMMOS. Figure 4 shows $E_{\text {act }}$ of $\mathrm{H}_{2}$ permeation through the membranes shown in Figure 3. $E_{\text {act }}$ of $\mathrm{H}_{2}$ permeation indicates the density of the deposited silica. $E_{\text {act }}$ increased with increasing the deposition temperatures. $E_{\text {act }}$ was $10 \mathrm{~kJ} \mathrm{~mol}^{-1}$ at $600^{\circ} \mathrm{C}$ of the TMMOS deposition, while $E_{\text {act }}$ was $22 \mathrm{~kJ} \mathrm{~mol}^{-1}$ for the TMOS deposition at $600^{\circ} \mathrm{C}$ (Nomura et al., 2005a). These differences must be the effect of methyl groups of the silica precursors. However, $\mathrm{H}_{2} / \mathrm{N}_{2}$ permeances ratio was enough high showing that the pore size of the membranes were around $0.3 \mathrm{~nm}$.

Hydrothermal stability is very important properties for hydrogen permselective membranes. Figure 5 


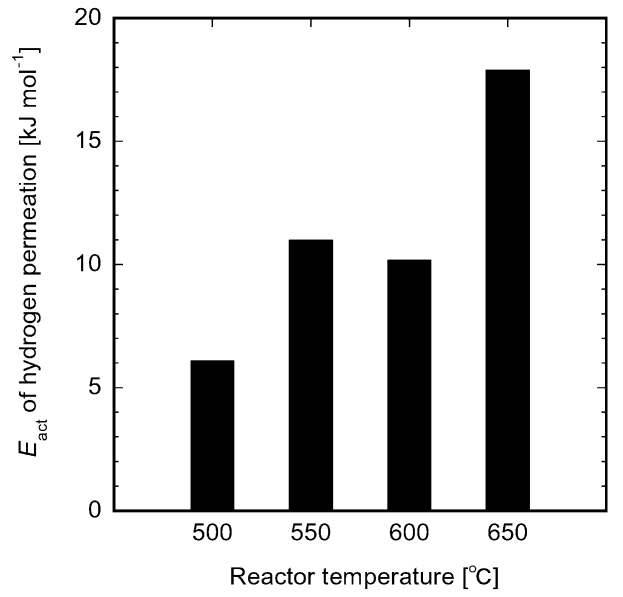

Fig. 4 Activation energies of $\mathrm{H}_{2}$ permeation through the silica membranes

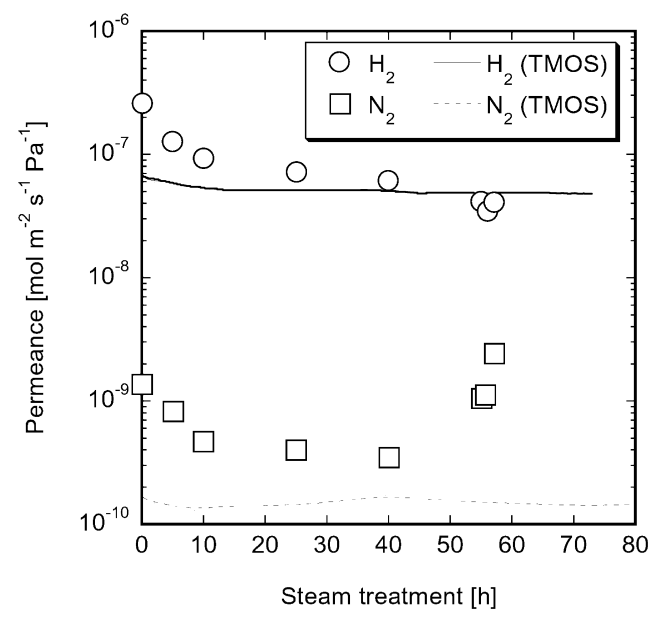

Fig. 5 Hydrothermal stability of the TMMOS membrane deposited at $600^{\circ} \mathrm{C}$. TMOS data were from the former literature (Nomura et al., 2006b)

shows the time course of $\mathrm{H}_{2}$ and $\mathrm{N}_{2}$ peremances through the membrane deposited at $600^{\circ} \mathrm{C}$ under $75 \%$ of steam at $500^{\circ} \mathrm{C}$. The solid line and the dotted line in the figure show $\mathrm{H}_{2}$ and $\mathrm{N}_{2}$ permeances through the membrane prepared by TMOS (Nomura et al., 2006b). Both $\mathrm{H}_{2}$ and $\mathrm{N}_{2}$ permeances decreased sharply at the initial steam treatment for the TMMOS membrane. $\mathrm{H}_{2}$ and $\mathrm{N}_{2}$ peremances decreased $50 \%$ and $40 \%$ in $5 \mathrm{~h}$ of steam treatment, respectively. This can be explained by densification of the deposited silica. On the other hand, the permeances differences for the TMOS membrane were about $10 \%$ in the first $5 \mathrm{~h}$ of steam treatment. $E_{\text {act }}$ of $\mathrm{H}_{2}$ permeation for the initial TMMOS membrane $\left(10 \mathrm{~kJ} \mathrm{~mol}^{-1}\right)$ was much smaller than that for the initial TMOS membrane $\left(22 \mathrm{~kJ} \mathrm{~mol}^{-1}\right)$ as shown in Figure 4. Low density silica must be easy to shrink compared with high density silica. After $10 \mathrm{~h}$ of steam treatment, $\mathrm{N}_{2}$ permeances look stable for the TMMOS membrane

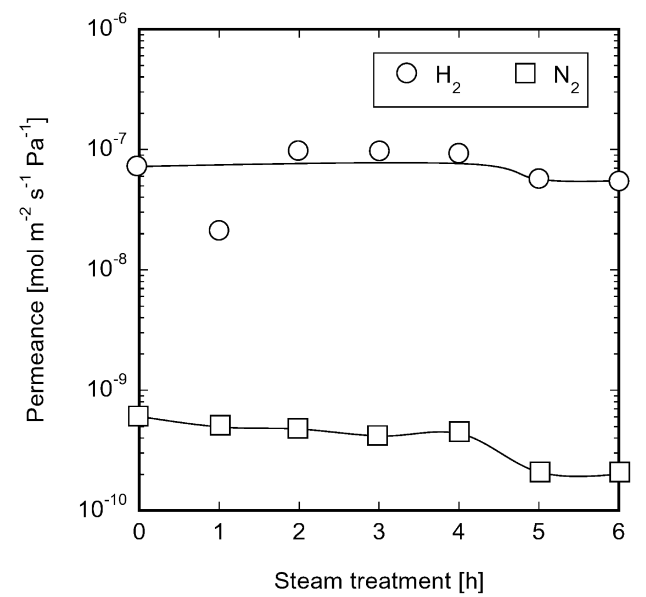

Fig. 6 Hydrothermal stability of the TMMOS membrane deposited at $650^{\circ} \mathrm{C}$

for 30 h. However, $\mathrm{N}_{2}$ permeances increased sharply after $50 \mathrm{~h}$ of steam treatment. $\mathrm{H}_{2} / \mathrm{N}_{2}$ permeances ratio was only 17 , and the membrane was broken by the treatment. The TMOS membrane was stable for more than $80 \mathrm{~h}$. The effect of deposition temperatures on hydrothermal stability was tested. Figure 6 shows the stability test for the TMMOS membrane deposited at $650^{\circ} \mathrm{C}$. The stability test was conducted for $6 \mathrm{~h} . \mathrm{H}_{2}$ permeances decreased only $20 \%$ by the first $5 \mathrm{~h}$ of treatment. The densification must be moderatefor the membrane deposited at $650^{\circ} \mathrm{C}$. $E_{\text {act }}$ of $\mathrm{H}_{2}$ permeation was $17.9 \mathrm{~kJ} \mathrm{~mol}^{-1}$ for the initial membrane that is similar to the membrane after the $6 \mathrm{~h}$ of steam treatment $\left(17.3 \mathrm{~kJ} \mathrm{~mol}^{-1}\right)$. Thus, the TMMOS membrane deposited at $650^{\circ} \mathrm{C}$ should be stable compared with that deposited at $600^{\circ} \mathrm{C}$. $E_{\text {act }}$ of $\mathrm{H}_{2}$ permeation is one of the key parameters for the hydrothermal stability of the membrane.

\subsection{PrTMOS deposition}

First, reactor temperatures for PrTMOS depositions were discussed. Figure 7 shows $\mathrm{H}_{2} / \mathrm{N}_{2}$ and $\mathrm{N}_{2} / \mathrm{SF}_{6}$ permeances ratios through the membranes deposited between 400 and $600^{\circ} \mathrm{C}$ from the $0^{\circ} \mathrm{C}$ of the PrTMOS bubbler. $\mathrm{H}_{2}$ permeances were also shown in the top of the figure.

$\mathrm{H}_{2} / \mathrm{N}_{2}$ permeances ratio increased with increasing deposition temperatures. $\mathrm{H}_{2} / \mathrm{N}_{2}$ and $\mathrm{N}_{2} / \mathrm{SF}_{6}$ permeances ratios were very low at $400^{\circ} \mathrm{C}$ of deposition, and the $E_{\text {act }}$ of $\mathrm{H}_{2}$ permeation was negative. This trend is similar to the $\gamma$-alumina substrate (Knudsen diffusion). Decomposition of PrTMOS was not enough at $400^{\circ} \mathrm{C}$. $\mathrm{H}_{2} / \mathrm{N}_{2}$ permeances ratio of $600^{\circ} \mathrm{C}$ of deposition was 35 , however this is much lower than that through the TMMOS membrane shown in Figure 3 (i.e., 211 at $600^{\circ} \mathrm{C}$ ). Thus, larger pore size can be obtained from PrTMOS. So, effects of bubbler temperatures on membrane performances were investigated at $500^{\circ} \mathrm{C}$ of the deposition temperature. 


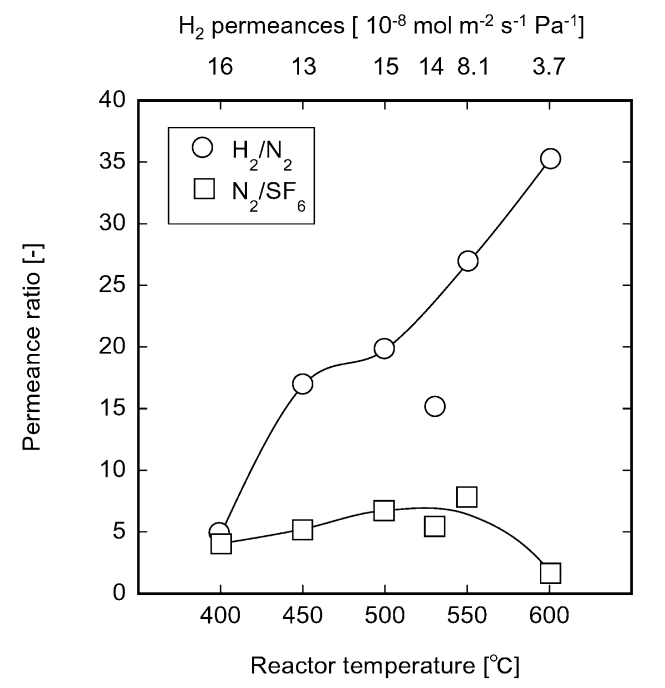

Fig. 7 Effects of reactor temperatures for the silica membranes prepared from $0^{\circ} \mathrm{C}$ of PrTMOS bubbler
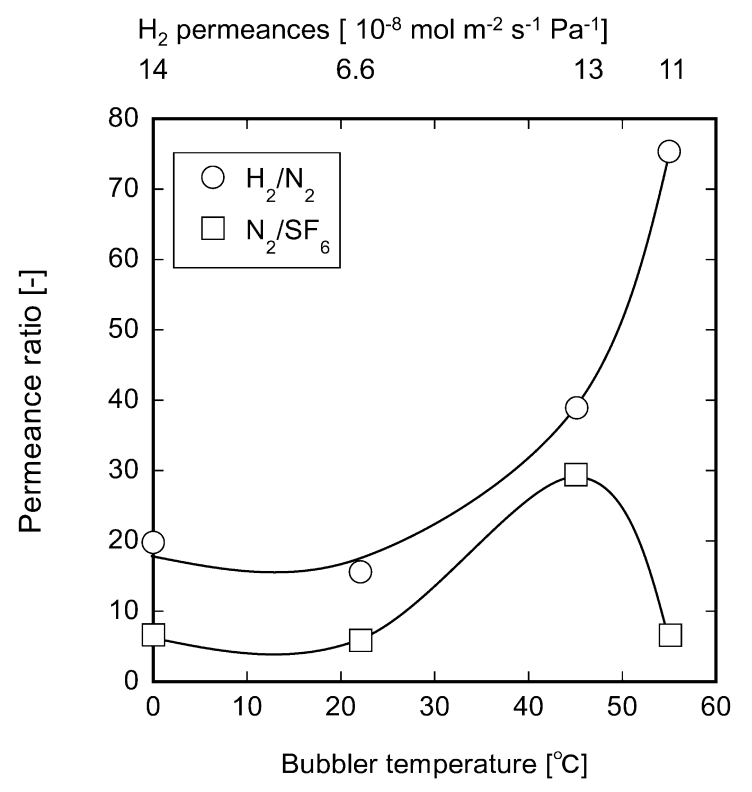

Fig. 8 Effects of bubbler temperatures of PrTMOS deposited at $500^{\circ} \mathrm{C}$

Figure 8 shows the single gas permeation measurements by changing the bubbler temperatures between 0 and $55^{\circ} \mathrm{C}$. Bubbler temperatures lower than $23^{\circ} \mathrm{C}, \mathrm{H}_{2} / \mathrm{N}_{2}$ and $\mathrm{N}_{2} / \mathrm{SF}_{6}$ permeances ratios were less than 20 and 7 , respectively. Permeances ratios of $\mathrm{H}_{2} / \mathrm{N}_{2}$ and $\mathrm{N}_{2} / \mathrm{SF}_{6}$ through a $\gamma$-alumina substrate were 3.7 and 2.3 which are based on the Knudsen diffusion mechanism. This shows that both permeances ratios were not so high for a molecular sieve membrane. Thus, we concluded that vapor pressures of PrTMOS below $23^{\circ} \mathrm{C}$ were not enough to produce a molecular sieve silica membrane. $\mathrm{H}_{2} / \mathrm{N}_{2}$ permeances ratios increased

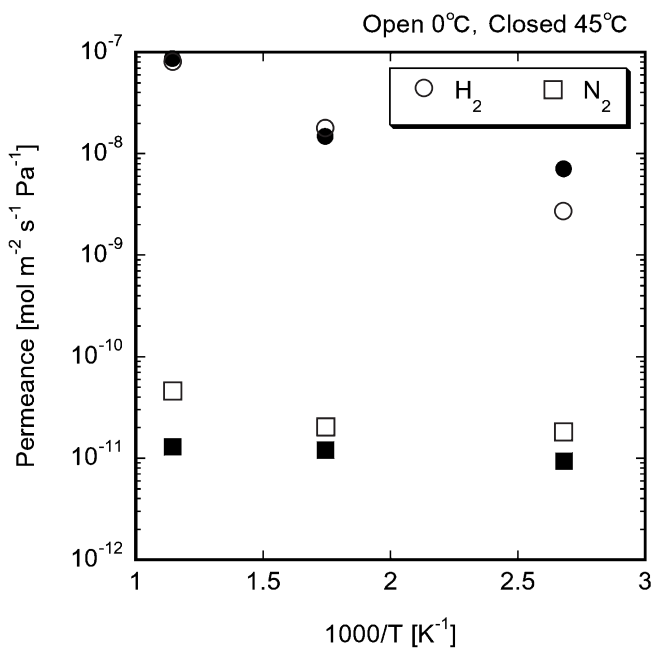

Fig. 9 Arrhenius plots of single gas permeances of TMOS membrane deposited at $600^{\circ} \mathrm{C}$ by changing bubbler temperatures

with increasing bubbler temperature above $45^{\circ} \mathrm{C}$. $\mathrm{H}_{2} / \mathrm{N}_{2}$ was 75 at $55^{\circ} \mathrm{C}$ of the PrTMOS bubbler. On the other hands, $\mathrm{N}_{2} / \mathrm{SF}_{6}$ permeances ratios showed the maximum (30) at the $45^{\circ} \mathrm{C}$ of the bubbler temperature. $\mathrm{N}_{2} / \mathrm{SF}_{6}$ permeances ratio at $55^{\circ} \mathrm{C}$ of the bubbler temperature was only 6.6. According to this result, pore size of the membrane deposited by the $45^{\circ} \mathrm{C}$ of the PrTMOS bubbler slightly increased with the TMOS membrane. Next, the silica membrane was deposited at $600^{\circ} \mathrm{C}$ from the $45^{\circ} \mathrm{C}$ of the PrTMOS bubbler temperature. $\mathrm{H}_{2}$ permeance was $1.2 \times 10^{-7} \mathrm{~mol} \mathrm{~m}^{-2} \mathrm{~s}^{-1} \mathrm{~Pa}^{-1}$, and $\mathrm{H}_{2} / \mathrm{N}_{2}$ and $\mathrm{N}_{2} / \mathrm{SF}_{6}$ permeances ratios were 75.2 and 1.1 , respectively. This membrane is hydrogen permselective membrane that is similar to the membrane prepared from $0^{\circ} \mathrm{C}$ of the PrTMOS bubbler (Figure 7). Thus, the deposition conditions are quit severe to obtain a molecular sieve silica membrane having high $\mathrm{N}_{2} / \mathrm{SF}_{6}$ permeances ratio.

Effects of TMOS bubbler temperatures between 0 and $45^{\circ} \mathrm{C}$ were also discussed. Figure 9 shows the Arrehnius plots of $\mathrm{H}_{2}$ and $\mathrm{N}_{2}$ permeances through the membrane prepared at 0 and $45^{\circ} \mathrm{C}$. Permeation properties look similar indicating that the bubbler temperatures between 0 and $45^{\circ} \mathrm{C}$ are not essential difference. The boiling temperatures of TMOS and PrTMOS are $121^{\circ} \mathrm{C}$ and $142^{\circ} \mathrm{C}$, respectively. This indicates that vapor pressures of TMOS are higher than that of PrTMOS at the same bubbling temperatures.

\subsection{Effects of silica precursors}

Effects of 4 silica precursors (TMOS, MTMOS, PrTMOS, and PhTMOS) on the permeation properties through the silica membranes were summarized by keeping the bubbler temperatures at $45^{\circ} \mathrm{C}$ and the reactor temperature at $500^{\circ} \mathrm{C}$. Figure 10 shows the permeation results through the membrane prepared from 


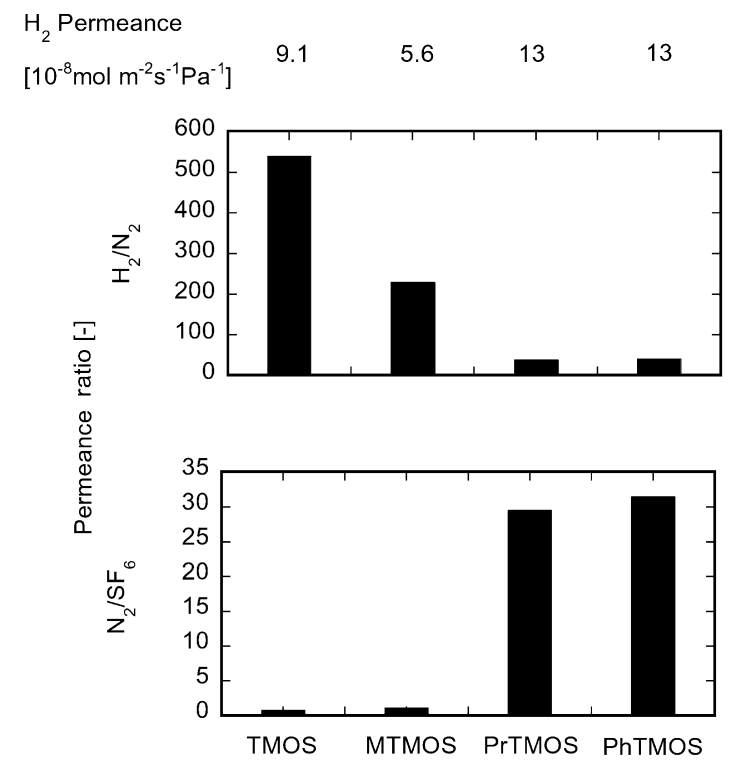

Fig. 10 Effects of silica precursors on permeation properties through the silica membranes deposited at $500^{\circ} \mathrm{C}$ for $45^{\circ} \mathrm{C}$ of the precursor bubblers

TMOS, MTMOS, PrTMOS and PhTMOS. It is obvious that $\mathrm{H}_{2} / \mathrm{N}_{2}$ permeances ratios and $\mathrm{N}_{2} / \mathrm{SF}_{6}$ permeances ratios show the negative relation. $\mathrm{H}_{2}$ permselective silica membranes were obtained from the smaller silica precursors such as TMOS or MTMOS. $\mathrm{H}_{2} / \mathrm{N}_{2}$ permecnces ratios were over 200 , while $\mathrm{N}_{2} / \mathrm{SF}_{6}$ permeances ratios were around 1 indicating that the pore sizes of the membranes were about $0.3 \mathrm{~nm} . \mathrm{N}_{2}$ permselective silica membrane was obtained from the larger silica precursors such as PrTMOS or PhTMOS. $\mathrm{N}_{2} / \mathrm{SF}_{6}$ permeances ratios through the membranes prepared by PrTMOS or PhTMOS were 30 and 32 , respectively. Those values are much larger than that of Knudsen diffusion $\left(\mathrm{N}_{2} / \mathrm{SF}_{6}=2.3\right) . \mathrm{H}_{2} / \mathrm{N}_{2}$ permeances ratios through the membranes were about 40 showing that the maximum pore sizes are around $0.5 \mathrm{~nm}$. These results show that the pore size of silica membranes can be controlled by changing the silica precursors. XPS cross-sectional observations were carried out for the PhTMOS membrane. There was no carbon was found from the membrane showing that the phenyl group in PhTMOS was completely fired to obtain a silica membrane.

\section{Conclusions}

Effects of 5 silica precursors (TMOS, MTMOS, TMMOS, PrTMOS, and PhTMOS) on the permeation properties through the silica membranes were investigated. Hydrogen permselective silica membrane was prepared by the counter diffusion CVD using TMOS, MTMOS and TMMOS. Methyl groups in the silica precursors might be small to obtain larger pore size membrane. The membranes having high $\mathrm{N}_{2} / \mathrm{SF}_{6}$ permeances ratio (ca. 30) were deposited from larger silica precursors such as PrTMOS or PhTMOS. However, $\mathrm{H}_{2} / \mathrm{N}_{2}$ permeances ratio increased at higher deposition temperatures from PrTMOS. This shows that the deposition conditions for a molecular sieve silica membrane (high $\mathrm{N}_{2} / \mathrm{SF}_{6}$ permeances ratio) need optimization. There were no carbon was found from the PhTMOS membrane deposited at $500^{\circ} \mathrm{C}$ by the XPS measurement. The deposited membrane was confirmed as a silica membrane by the measurements.

\section{Acknowledgements}

This work has been partially supported by the Ministry of Education, Science, Sports and Culture of Japan, Grant-in-Aid for Young Scientists (A), 17686065, 2005. Authors thank Dr. Aiko Nakao of Riken, Japan for the XPS measurements.

\section{Literature Cited}

Gavalas, G. R., C. E. Megiris and S.-W. Nam; "Deposition of $\mathrm{H}_{2}$ Permselective $\mathrm{SiO}_{2}$ Films," Chem. Eng. Sci., 44, 1829-1835 (1989)

Gopalakrishnan, S., M. Nomura, T. Sugawara and S. Nakao; "Preparation of a Multi Membrane Module for High Temperature Hydrogen Separation," Desalination, 193, 230-235 (2006)

Ha, H.-Y., S.-W. Nam, S.-A. Hong and W.-K. Lee; "Chemical Vapor Deposition of Hydrogen-Permselective Silica Films on Porous Glass Supports from Tetraethylorthosilicate," J. Membr. Sci., 85, 279-290 (1993)

Kanezashi, M. and M. Asaeda; "Hydrogen Permeation Characteristics and Stability of Ni-Doped Silica Membranes in Steam at High Temperature," J. Membr. Sci., 271, 86-93 (2006)

Kurungot, S., T. Yamaguchi and S. Nakao; " $\mathrm{Rh} / \gamma-\mathrm{Al}_{2} \mathrm{O}_{3}$ Catalytic Layer Integrated with Sol-Gel Synthesized Microporous Silica Membrane for Compact Membrane Reactor Applications," Catal. Lett., 86, 273-278 (2003)

Kusakabe, K., S. Sakamoto T. Saie and S. Morooka; "Pore Structure of Silica Membranes Formed by a Sol-Gel Technique Using Tetraethoxysilane and Alkyltriethoxysilanes," Sep. Purif. Technol., 16, 139-146 (1999)

Lee, D., L. Zhang, S. T. Oyama, S. Niu and R. F. Saraf; "Synthesis, Characterization, and Gas Permeation Properties of a Hydrogen Permeable Silica Membrane Supported on Porous Alumina," J. Membr. Sci., 231, 117-126 (2004)

Morooka, S., S.-C. Yan, K. Kusakabe and Y. Akiyama; "Formation of Hydrogen-Permselective $\mathrm{SiO}_{2}$ Membrane in Macropores of $\alpha$-Alumina Support Tube by Thermal Decomposition of TEOS," J. Membr. Sci., 101, 89-98 (1995)

Nair, B. N., T. Okubo and S. Nakao; "Structure and Separation Properties of Silica Membranes," Membrane, 25, 73-85 (2000)

Nakao, S., T. Suzuki, T. Sugawara, T. Tsuru and S. Kimura; "Preparation of Microporous Membranes by TMOS/O $\mathrm{O}_{3} \mathrm{CVD}$ in the Opposing Reactants Geometry," Microporous Mesoporous Mater., 37, 145-152 (2000)

Nomura, M., T. Yamaguchi, I. Kumakiri and S. Nakao; "Permeation Properties and Microstructure of Porous Inorganic Membranes" (in Japanese), Membrane, 26, 124-133 (2001)

Nomura, M., K. Ono, S. Gopalakrishnan, T. Sugawara and S. Nakao; "Preparation of a Stable Silica Membrane Using a Counter Diffusion Chemical Vapor Deposition Method," J. Membr. Sci., 251, 151-158 (2005a)

Nomura, M., S. Gopalakrishnan, H. Aida, T. Sugawara, S. Nakao, S. Yamazaki, Y. Iwamoto, R. Kojima and A. Nakao; "Investigation of a Hydrothermal Stable Hydrogen Permselective Silica Membrane for a Large Membrane Area Module" (in Japanese), Membrane, 30, 275-281 (2005b) 
Nomura, M., H. Aida, S. Gopalakrishnan, T. Sugawara, S. Nakao, S. Yamazaki, T. Inada and Y. Iwamoto; "Steam Stability of a Silica Membrane Prepared by a Counter Diffusion Chemical Vapor Deposition," Desalination, 193, 1-7 (2006a)

Nomura, M., H. Aida, K. Nakatani, S. Gopalakrishnan, T. Sugawara, S. Nakao, M. Seshimo, T. Ishikawa and M. Kawamura; "Preparation of a Catalyst Composite Silica Membrane Reactor for Steam Reforming Reactions Using a Counter Diffusion CVD Method," Ind. Eng. Chem. Res., 45, 3950-3954 (2006b)

Oyama, S. T., D. Lee, P. Hacarlioglu and R. F. Saraf; "Theory of Hydrogen Permeability in Nonporous Silica Membranes," J. Membr. Sci., 244, 45-53 (2004)

Prabhu, A. K. and S. T. Oyama; "High Hydrogen Selective Ceramic Membranes: Application to the Transformation of Greenhouse Gases," J. Membr. Sci., 176, 233-248 (2000)

Raman, N. K. and C. J. Brinker; "Organic 'Template' Approach to
Molecular Sieve Silica Membranes," J. Membr. Sci., 105, 273279 (1995)

Tsuru, T., K. Yamaguchi, T. Yoshioka and M. Asaeda; "Methane Steam Reforming by Microporous Catalytic Membrane Reactors," AIChE J., 50, 2794-2805 (2004)

Uemiya, S.; "State-of-the-Art of Supported Metal Membranes for Gas Separation," Sep. Purif. Methods, 28, 51-85 (1999)

Yamaguchi, T., X. Ying, Y. Tokimasa, B. N. Nair, T. Sugawara and S. Nakao; "Reaction Control of Tetraethyl Orthosilicate (TEOS) $/ \mathrm{O}_{3}$ and Tetramethyl Orthosilicate (TMOS) $/ \mathrm{O}_{3}$ Counter Diffusion Chemical Vapor Deposition for Preparation of Molecular-Sieve Membranes," Phys. Chem. Chem. Phys., 2, 44654469 (2000)

Yoshino, Y., T. Suzuki, B. N. Nair, H. Taguchi and N. Itoh; "Development of Tubular Substrates, Silica Based Membranes and Membrane Modules for Hydrogen Separation at High Temperature," J. Membr. Sci., 267, 8-17 (2005) 